\title{
The Strategic Decisions of Short-term Rental Investment Startup Companies in the Context of COVID-19
}

\author{
Ruitong Yang, *
}

\author{
${ }^{I}$ Southwest University, Chongqing 400700, China \\ *Ruitong Yang. Email: ritayrt0601@email.swu.edu.cn|
}

\begin{abstract}
The world economy was experiencing a considerable slowdown due to the COVID-19 spread. Despite the expected strong recoveries of economies, companies are still at great risks during post COVID-19 time. The key to survival is how they can adjust their corporate strategies with the help of unprecedented country fiscal, monetary, and regulatory responses under elevated uncertainties. This paper combined SWOT analysis and analytical hierarchy process (AHP) and experts' professional instructions to obtain quantitative strategic quadrilateral, strategic azimuth and intensity coefficient. Based on the results, reAlpha is supposed to adopt the pioneering strategy of seizing opportunities. And strategy implementations of OS, OW, ST and WT are scientifically further clarified as suggestions.
\end{abstract}

Keywords: strategic decision, startup, COVID-19, SWOT-AHP

\section{INTRODUCTION}

COVID-19 has led to massive elevations in uncertainty which is one of the major obstacles to business growth. U.S. statistics prove that year-over-year GDP contracts by $11 \%$ in the fourth quarter of 2020 , more than half of which is caused by COVID-19-induced uncertainty [1]. Even worse, Coibion et al. found that primarily containments, rather than the infections themselves, lead to contraction [2]. Bogliacino et al. find that a negative shock triggered by COVID-19 lowers cognitive functionality and increases risk aversion [3]. And this slipping consumer confidence serves as a proxy for pessimism [4]. Mostly because of those, immature startups are hard to survive in the post-epidemic era. Therefore, their corporate strategy matters.

Corporate strategy is initial in corporate management. If companies want to survive and maintain long-term development, they should formulate reasonable strategies based on internal and external environments. Andrews proposed the framework of SWOT analysis to draw strategic decisions [5]. On this basis, Wang and Gan proposed using expert opinions, plane coordinate systems, and strength calculations to construct a more accurate and quantitative analysis system [6]. Then Mikko first combined Analytic Hierarchy Process (AHP) and SWOT together to better solve strategy making problems with the various weighting of factors [7]. As the SWOT-AHP method has been developing, its application range continues to expand. Yang applied SWOT quantitative analysis model to formulate theme park strategies, which provides a useful reference in the industry [8]; Zeng (2015) launched research on real estate company strategies based on SWOT analysis [5]; Liu et al. used SWOT-AHP to make strategic decisions of coastal tourism [9]; Laroche et al. investigated the factors influencing local stakeholders' decision to integrate agroforestry intercropping systems and their perception of the relative suitability of the designs through SWOTAHP [10].

This paper connects two scarcely investigated streams of research: the strategic decisions of a shortterm rental investment startup company in the context of COVID-19. Though many scholars are increasingly interested in the separate themes, there is a large gap in the literature that focuses on the interconnections between short-term rental investment and corporation strategies towards COVID-19. The paper contributes to relevant literatures: first, it objects to fill the research gap of the short-term rental industry during COVID-19. Second, it documents a case study on reAlpha company in the US, represented among the hot short-term rental investment industry worldwide. Third, most strategic decisions are based on qualitative methods, namely 
SWIOT, PEST while lacking quantitative analysis based on analyzing statistics. Quantitative analysis provides startup companies opportunities in the light of objective and specific goals. Additionally, concerning the downturn worldwide, the strategies may provide guidelines and references.

\section{DATA AND METHOD}

\subsection{Data}

reAlpha.com is a digital marketplace that simplifies, finances, and manages short-term rental investments. Founding in 2018, the US, reAlpha aims to become the nation's largest short-term rental property owner and is planning to purchase up to 15,000 Airbnb rentals over 5 years. Now it is in reg A+ equity crowdfunding round. reAlpha sources and scores properties from the market by AI algorithm-reAlphaBRAIN. It predicts the viability of each property for the short-term rental market and the projected long-term value. Properties with the highest scores are listed on the reAlpha platform to provide wealth generation opportunities for everyone: short-term rental income through Airbnb as well as equity-driven capital appreciation.

\subsection{Method}

\subsubsection{SWOT Analysis}

SWOT stands for Strengths, Weaknesses, Opportunities and Threats, among which strengths and weaknesses are internal factors, while opportunities and threats are external factors [11]. Therefore, companies should strengthen their strengths grasp, try to overcome weaknesses and avoid or mitigate threats opportunities to formulate the optimal strategic plans.

\subsubsection{AHP Analysis}

After SWOT analysis building successful strategies, the analytic hierarchy process (AHP) provides evaluations.

The analytic hierarchy process (AHP) is one of the most practical multi-criterion decision-making techniques used for solving and analyzing complex problems. The AHP can estimate both qualitative and quantitative elements [12]. It consists of structuring the AHP hierarchy, including an objective, decision criteria, sub-criteria, and available alternatives, weight criteria using Saaty's scale, and determining and ranking final alternatives [13].

Step 1: Identify SWOT factors.
Table 1. SWOT model

\begin{tabular}{c|c|c|c}
\hline External & & Strengths & Weaknesses \\
\hline Opportunities & & SO & WO \\
\hline Threats & & ST & WT \\
\hline
\end{tabular}

Step 2: Calculate factor score.

Step 3: Structure AHP hierarchy and construct pairwise comparison matrix A.

$$
A=\left(a_{i j}\right)=\left(\begin{array}{cccc}
a_{11} & a_{12} & \cdots & a_{1 n} \\
a_{21} & a_{22} & \cdots & a_{2 n} \\
\vdots & \vdots & \ddots & \vdots \\
a_{n 1} & a_{n 2} & \cdots & a_{n n}
\end{array}\right)
$$

$a_{i j}$ is the degree of importance for $\mathrm{i}$ relative to $\mathrm{j}$ in SWOT, and $a_{i j}=\frac{1}{a_{j i}}$. Specially, when $\mathrm{i}=\mathrm{j}, a_{i j}=1$. The ninth-quantile proportional scale varying 1 to 9 is introduced to judge the relative importance of indexes, and 9 shows extreme or absolute importance, while 1 represents equality [14].

Step 4: Use the eigenvector method to obtain the normalizing eigenvector $\left(w_{i}\right)$ and maximum eigenvalue $\left(\lambda_{\max }\right)$ of the pairwise comparison matrix [14].

$$
\begin{aligned}
& w_{i}=\frac{\vec{W}_{i}}{\sum_{j=1}^{n} \vec{W}_{j}}(j=1,2 \cdots, n) \\
& \vec{W}_{i}=\sqrt[n]{\prod_{i=1}^{n} a_{i j}}(i=1,2, \cdots n) \\
& \lambda_{\max }=\frac{1}{n} \sum_{i=1}^{n} \frac{(A w)_{i}}{w_{i}}(3)
\end{aligned}
$$

Step 5: Consistency test. Satty (2008) defined a consistency index (CR) by a formula (below). Matrices of size $n$ randomly generate $\mathrm{RI}$, random index. Only a CR value is less than 0.1 is acceptable. Otherwise, the pairwise comparison matrix needs to be adjusted, and the decision-maker must re-evaluate the decisions [15].

Step 6: Calculate factor intensity. Referencing and improving the research of Wang and Gan, the intensity of each strategic factor is defined as follows [2]:

$$
\begin{aligned}
& S_{\mathrm{i}}=I_{i} \cdot P_{i}(i=1,2,3 \cdots, n) W_{j}=I_{j} \cdot P_{j}(j=1,2,3 \cdots, n) \\
& O_{k}=I_{k} \cdot P_{k}(k=1,2,3 \cdots, n) T_{l}=I_{l} \cdot P_{l}(l=1,2,3 \cdots, n)
\end{aligned}
$$


Among them $S_{i}, W_{j}, O_{k}, T_{l}, I, P$ represent the intensity of each strength, weakness, opportunity, threat factor, and factor score and relative importance (weight), respectively.

Step 7: Establish the optimal strategic type and implementation type according to the final intensities, strategic quadrilateral, azimuth and intensity coefficient. And the final intensity is calculated as:

$$
\begin{aligned}
& S=\sum_{i=1}^{n} S_{i}(i=1,2 \cdots n) ; W=\sum_{j=1}^{n} W_{j}(j=1,2 \cdots n) \\
& O=\sum_{k=1}^{n} O_{k}(k=1,2 \cdots n) ; T=\sum_{l=1}^{n} S_{l}(l=1,2 \cdots n)
\end{aligned}
$$

\section{RESULTS AND DISCUSSION}

Although SWOT analysis is a popular technique in strategic planning, the SWOT method has no corresponding data support, lacks a quantitative analysis process, and only draws a qualitative description of the conclusion, which is highly subjective. AHP is a key multicriteria decision-making method to select superior strategies on particular criteria. Hybrid AHP-SWOT analysis can reach a combination of qualitative and quantitative, which is widely used in real-estate investment strategic decision making.

\subsection{SWOT Analysis}

Based on the actual statistics accessible online and previous research, the strengths, weaknesses, opportunities, and threats of reAlpha are shown below.

\subsection{Strength}

S1: Strong entrepreneurial team. A world-class team of experts who are seasoned in the real estate industry are built as leadership. The Advisory board and directors of the board are composed of individuals with high qualifications and abundant experience. Also, young and creative employees are making valuable contributions to the business.

S2: Unique business model. First, reAlpha requires a lower down payment which is $10 \%$ of their investment properties compared with the general $25 \%$ in the market. And as like-minded investors are paired into syndicates, the fractional ownership adds up to cover the down payment together, which makes it more affordable. Second, reAlpha provides a unique yield model for investors. Real estate investment allows members to benefit from both the superior returns of short-term rental income and the increase in property value through renovation and appreciating. Then in terms of real estate, short-term rentals outstand in their stability, guaranteed income and versatility. They will always have intrinsic value, which is tangible, real and creates wealth over time, compared with the high volatility of stocks. Furthermore, short-term rentals always provide a higher yield than others, namely REITs and S\&P 500, experiencing longrun slow growth historically, which even hold a negative return due to COVID-19 in 2020.

S3: Advanced incentive policy. reAlpha is also part of each syndicate, retaining $51 \%$ ownership of each property. The aligned interests provide less contradiction and additional security to investors, strengthening their confidence and preference towards reAlpha.

S4: Proprietary AI algorithm is employed for smarter investment. reAlpha's AI algorithm, the reAlphaBRAIN, will go through the sourcing to selling process to help make the most intelligent investor choices. First, it would score each property based on 28 different factors after sourcing properties from the wholesale market. Then, it predicts the viability of each property for the short-term rental market and the projected long-term value. The highest score short-term properties would be approved for investors and then rented on Airbnb to obtain a continuous flow of income and extract maximum value at the best selling time based on reAlphaBRAIN prediction.

\subsection{Weakness}

W1: Control risk. reAlpha is now experiencing a high risk of controlling due to their low proportion of stocks. Based on crunchbase [17]information, reAlpha has raised a total of $\$ 6.1$ million in 3 rounds. CEO of reAlpha contributes $\$ 100,000$ while Crawford Hoying, a realestate development firm, invested \$6 million (more than $98 \%$ ) in pre seed and seed rounds.

W2: Financing risk. Founders may criticize the independence problems of control concerning dilution. On the other hand, insufficient funds may severely block their development as a real estate investment company that needs a strong fund background. And it's before the IPO stage narrows funding channels, which makes reAlpha get along with the money constraint even harder.

W3: Startup risk. Trapped in less reputation, investors have little confidence and knowledge towards reAlpha. The only tiny influx of customers would flow to reAlpha. Syndicates of like-minded investors are hard to build. Although team members are brilliant in the field, the number of them is limited. In addition, to the direct of boards and advisory board, only 11 employees are working. Small team bears complex and large operation, reAlpha's capacity may impede its expansion. Considering various future departments, uncertain situations, and unpredictable customer numbers, it remains doubtful whether it is organized and efficiently. Also, due to its immaturity and low market power, reAlpha has little access to suitable resources. Companies in this field have to nab homes at below-market prices if 
they want to survive. But reAlpha now only intends to snag properties at a discount following the end of the federal foreclosure moratorium.

\subsection{Opportunity}

O1: Short-term rental industry has a bright outlook. Forecasted by reAlpha, there will be 7.4 million shortterm rental properties, and its annual revenue will reach \$1.2 trillion globally. And specifically for the USA, there will be 1.8 million short-term rental properties worth $\$ 933$ billion. Appeal to business rests on the potential size of its market.

O2: Macroeconomy provides a beneficial environment. The economy has witnessed a carryover from 2020, sectors including travel, leisure and crossborder study exposing to a higher risk of COVID-19 begun to shift into high gears and have a robust recovery as the vaccine proceeds and social distancing relaxes. Experts in the Conference Board Economic [18] pointed that U.S. real GDP rose at a $6.4 \%$ annual rate in the first quarter and expected the full year 2021 to match $6 \%$. Specifically, in the house sale market, the median homesale price of the U.S. increased $15 \%$ year over year from 2020 . $52 \%$ of homes sold above list price, but this has even softened since it peaked at 55\% from 2020 [19].

O3: Demand increasing. The U.S. always has a large potential housing market. Statistics provided by Pew research Center [20] prove that the U.S. takes in more than 1 million immigrants every year. Epidemic provides additional opportunities further. CoStar [21] showed that demand for apartments rebounded quickly in the first quarter of 2021. The continuous growth of rental demand leads to constricted supply, resulting in a sharp drop in the U.S. vacancy index throughout the rapid increase of prices. Rents are now up more than 13 per cent this year, more than double the inflation. And according to the rent report from Apartment list [22], a U.S. house rental platform, rents are rising everywhere pre-pandemic except few cities but rebounding quickly. In San Francisco, for example, rents are still 12 per cent lower than they were in March 2020, but the city has seen prices increase by 20 per cent since January of 2021.

\subsection{Threat}

T1: COVID-19. The outbreak of the global pandemic has devastated the travel industry. According to the US travel association, [21] there will be $\$ 492.3$ billion loss in travel spending and $\$ 60$ million decreases in visitations, damaging the vacation short-term rentals market. Although statistics have proved that the economy is gradually recovering, commercial real estate markets lagged [16]. Even worse, abnormal inflation exists. April's annualized inflation is $4.2 \%$, breaking the record of the past decade. But concerning the "base-year effect" of shutdowns with extremely low price levels since 2019 , this situation may make sense.

T2: Competitors. Blackstone and Invitation Homes, namely, snap up homes by $\$ 50$ billion across the country to rent out for a profit. So giant and fierce competitors are threatening the very existence of reAlpha.

T3: Risk aversion. The increased levels of distress and anxiety after the pandemic greatly swallowed investor confidence.

The strengths, weaknesses, opportunities and threats in reAlpha are summarized in Table 2.

\subsection{Factor intensity}

\subsubsection{Factor score}

The factor score in this paper refers to the degree of strengths (weaknesses) of the reAlpha compared with its competitors and the grade of opportunities (threats) faced by estate investment during COVID-19. Referring to Wang and Chen (2010), the score is classified into

Table 2. SWOT of reAlpha

\begin{tabular}{lr}
\hline \multicolumn{1}{c}{ Strength(S) } & Weakness(W) \\
\hline S1: Strong entrepreneurial team & W1: Control risk. \\
S2: Unique product advantages. & W2: Financing risk \\
S3: Advanced management concepts. & W3: Startup risk. \\
S4: Proprietary Al algorithm & \\
Opportunity(O) & \\
O1: Bright industry outlook & T1: COVID-19 \\
O2: Beneficial macroeconomy & \\
environment & T2: Competitors
\end{tabular}

O3: Increasing demand

T3: Risk aversion.

nine grades, namely, $-4,-3,-2,-1,0,1,2,3,4$. Among them, the factor scores of strengths and opportunities are expressed by a positive value, while a negative value expresses the factor scores of weaknesses and threats. The greater the absolute value, the higher the factor scores. Consistent scores are obtained from experienced experts and relevant literatures in this field with the Delphi method, as shown in Table 4.

\subsubsection{Factor Weight}

After three rounds of opinion collecting and information feedback, a consistent result is obtained. According to the scores, pairwise comparison matrixes 
are given out. The pairwise comparison matrix $\mathrm{S}, \mathrm{W}, \mathrm{O}$, $\mathrm{T}$ are shown below.

After performing the matrix and consistency check, the calculated weights of all factors are shown in Table 3. And $\mathrm{A}$ is the intra-group comparison matrix.

\subsubsection{Factor intensity}

After performing the intensity equation, the final intensities of factors are obtained (Table 4).

\subsection{Strategic Type and Implementing Intensity}

\subsubsection{Strategic quadrilateral}

A four half dimension coordinate system is constructed by the four semi-axes of the four variables, strength, weakness, opportunity, and threat strength. Point $(0.809,0),(-0.3816,0),(0,1.4748)$ and $(0,-0.4889)$ are on the relevant half-axes in the coordinate system. And the strategic quadrilateral can be obtained by linking four points. (Figure 1)

\subsubsection{Strategic azimuth}

In the four half-dimensional planes, the type of strategy is determined by the barycentric coordinates of the strategic quadrilateral. For $S^{\prime} W^{\prime} O^{\prime} T^{\prime}$, its barycentric coordinates $\mathrm{P}(\mathrm{X}, \mathrm{Y})$ is:

$$
P(X, Y)=\left(\sum x_{i} / 4, \sum y_{i} / 4\right)=(0.10685,0.246475)
$$

Where $x_{i}$ and $y_{i}$ are respectively the coordinates of points $S^{\prime}, W^{\prime}, O^{\prime}$ and $T^{\prime}$ in the strategic quadrilateral. The azimuth angle is determined as:

$$
\tan \theta=Y / X(0 \leq \theta \leq 2 \pi)
$$

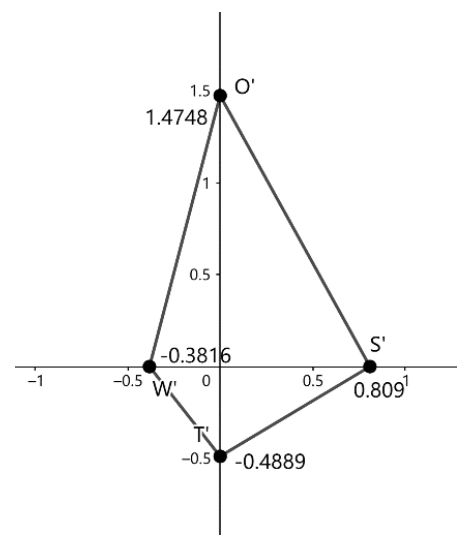

Figure 1. Strategic quadrilateral

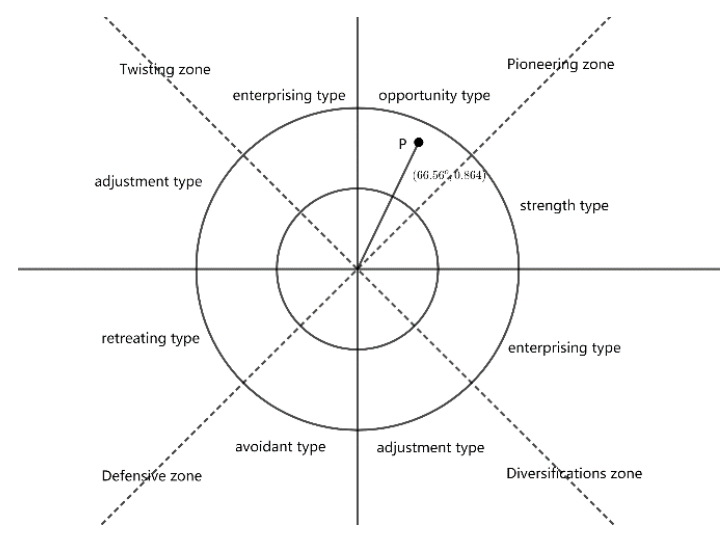

Figure 2. Strategy type and implementation

As $\theta=\arctan (0.246475 / 0.10685)=66.56^{\circ}$, the pioneering strategy of opportunities is more reasonable for reAlpha.

\subsubsection{Strategic intensity coefficient}

The intensity of strategy implementation is determined by the strategic intensity coefficient $\rho, \rho \in[0,1]$, which is affected by the combined positive intensity $\mathrm{U}$ and negative intensity $\mathrm{V}$. And they are defined as follows:

$$
\begin{aligned}
& \rho=U /(U+V)=0.8648 \\
& U=I_{S} \times I_{O}=1.19319 ; V=I_{W} \times I_{T}=0.18656
\end{aligned}
$$

When $\rho<0.5$, a conservative approach is recommended; while when $\rho \geq 0.5$, a progressive one is more suitable. Therefore, the implementation is encouraged to be more aggressive. (Figure 2)

\section{CONCLUSION}

Table 3. SWOT factors

\begin{tabular}{ccllll}
\hline & $\lambda_{\max }$ & \multicolumn{1}{c}{ Normalized eigenvector } & $\mathrm{n}$ & $\mathrm{CR}$ & Consistency test \\
\hline A & 4.1638 & $(0.2941,0.1201,0.4160,0.1698)$ & 4 & 0.0607 & $\mathrm{Y}$ \\
$\mathrm{S}$ & 4.1147 & $(0.2772,0.0829,0.5456,0.0942)$ & 4 & 0.0425 & $\mathrm{Y}$ \\
W & 3.0037 & $(0.1095,0.3090,0.5816)$ & 3 & 0.0036 & $\mathrm{Y}$ \\
\hline
\end{tabular}




\begin{tabular}{cccccc}
\hline $\mathrm{O}$ & 3.0183 & $(0.5584,0.1220,0.3196)$ & 3 & 0.0176 & $\mathrm{Y}$ \\
$\mathrm{T}$ & 3.0037 & $(0.2297,0.1220,0.6483)$ & 3 & 0.0036 & $\mathrm{Y}$ \\
\hline
\end{tabular}

Table 4. Scores, weights and intensities of SWOT

\begin{tabular}{|c|c|c|c|c|c|c|c|}
\hline & $\begin{array}{c}\text { Weight } \\
\text { between } \\
\text { groups }\end{array}$ & Factor & $\begin{array}{c}\text { Weight } \\
\text { among group }\end{array}$ & $\begin{array}{l}\text { Factor } \\
\text { score }\end{array}$ & $\begin{array}{c}\text { Final } \\
\text { weight }\end{array}$ & $\begin{array}{c}\text { Factor } \\
\text { intensity }\end{array}$ & $\begin{array}{c}\text { Group } \\
\text { intensity }\end{array}$ \\
\hline \multirow{4}{*}{$S$} & \multirow{4}{*}{0.2941} & S1 & 0.2772 & 2.4 & 0.0815 & 0.1956 & \multirow{4}{*}{0.8090} \\
\hline & & $\mathrm{S} 2$ & 0.0829 & 3.2 & 0.0244 & 0.0781 & \\
\hline & & S3 & 0.5456 & 2.8 & 0.1605 & 0.4494 & \\
\hline & & S4 & 0.0942 & 3.1 & 0.0277 & 0.0859 & \\
\hline \multirow{3}{*}{ W } & \multirow{3}{*}{0.1201} & W1 & 0.1095 & -3.5 & 0.0132 & -0.0462 & \multirow{3}{*}{-0.3816} \\
\hline & & W2 & 0.3090 & -3.2 & 0.0371 & -0.1187 & \\
\hline & & W3 & 0.5816 & -3.1 & 0.0699 & -0.2167 & \\
\hline \multirow{3}{*}{$\mathrm{O}$} & \multirow{3}{*}{0.4160} & O1 & 0.5584 & 3.6 & 0.2322 & 0.8359 & \multirow{3}{*}{1.4749} \\
\hline & & $\mathrm{O} 2$ & 0.1220 & 2.9 & 0.0508 & 0.1473 & \\
\hline & & O3 & 0.3196 & 3.7 & 0.1329 & 0.4917 & \\
\hline \multirow{3}{*}{$\mathrm{T}$} & \multirow{3}{*}{0.1698} & T1 & 0.2297 & -3.5 & 0.0390 & -0.1365 & \multirow{3}{*}{-0.4889} \\
\hline & & T2 & 0.1220 & -3.2 & 0.0207 & -0.0662 & \\
\hline & & T3 & 0.6483 & -2.6 & 0.1101 & -0.2862 & \\
\hline
\end{tabular}

The world economy was gripped tightly by the COVID-19 spread leading to a considerable slowdown. In spite of the expected strong recoveries of economies, companies are still poised at the brink of bankruptcy during post COVID-19 time. The key to survival is how they can adjust their corporate strategies under the combination of the help of unprecedented country fiscal, monetary, and regulatory responses and elevated uncertainties. This paper scientifically gives suggestions on strategy making and implementation with the help of SWOT analysis and analytical hierarchy process (AHP) and experts' professional instructions. And based on the results, reAlpha is supposed to adopt the pioneering strategy of seizing opportunities. With analysis outcomes, decision-makers can choose among the four kinds of strategy implementations.

\subsection{SO strategy}

Focus on strengths and take advantage of opportunities.

As the macroeconomic recovering continuous growth of rental demand heating up, reAlpha should utilize reAlphaBRAIN to source the wholesale market and purchase higher-score short-term rentals quickly to provide more property options for investors and obtain increasing income from Airbnb. Aided by the networks and influence of founders, reAlpha could absorb more talents to join. Their skilled team needs to concentrate on testing, improving, and updating the AI system to back up its valuation's accuracy, efficiency, and effectiveness. Furthermore, members should diversify and standardized reAlpha aligned syndicates incentive policy to outstand their guarantee safety.

\subsection{WO strategy:}

Use opportunities to make up for weaknesses.

With a bright and attractive outlook, reAlpha should accelerate the interaction with angel investors. They are supposed to seek help from venture capital companies providing mentorship. Despite the tremendous transfusion of funds, their network and powerful background, reAlpha has more potential to acquire resources before its IPO. Taking the huge potential of the short-term rental market, combined with the promising macroeconomic prospection, reAlpha should attract customers actively to remedy the insufficient funds from venture capitals, retain the profits in the company to strengthen its ownership, improve and consolidate its brand status of ever greening property investment.

\subsection{ST strategy}

Use strengths to reduce threats.

Relying on both human and artificial intelligence and the unique product advantages, reAlpha needs to aggressively promote and put investment plans into effect to earn profits and keep its operation. Their brilliant team members are supposed to innovate marketing to catch customers' interests. reAlpha need to explore and turn their own strengths into publicity. Thanks to reAlphaBRAIN, the AI algorithm develops more scientific, accurate and efficient investment plans for investors.

\subsection{WT strategy}

offset weakness to threats

Faced with dominant and greedy competitors, reAlpha need to be aware of merger and talent hunting 
risks primarily, they may adopt employee options with cliff vesting and pay them equal monthly installments to retain talents. Still, founders are recommended to negotiate with Crawford Hoying and create an unallocated option pool for employees to adjust the ownership structure. Moreover, reAlpha may acquire and merge downward local investment companies under the impact of COVID-19 and use their accumulated reputation to gain investor trust and self-promotion.

And as for targets, they can only focus on several cities first with their potential market and then step into national expansion until they have sufficient financial support.

\section{REFERENCES}

[1] Baker, S. R., Bloom, N., Davis, S. J., \& Terry, S. J. (2020). COVID-induced economic uncertainty. NBER Working Paper No. 26983. National Bureau of Economic Research. Cambridge, MA.

[2] Coibion, O., Gorodnichenko, Y., \& Weber, M. (2020). The cost of the Covid-19 crisis: Lockdowns, macroeconomic expectations, and consumer spending. NBER Working Paper No. 27141. National Bureau of Economic Research, Cambridge, MA.

[3] Bogliacino, F., Codagnone, C., Montealegre, F., Folkvord, F., Gómez, C. E., Charris, R. A., Liva, G., Villanueva, F. L., \& Veltri, G. A. (2020). Negative shocks predict change in cognitive function and preferences: Assessing the negative affect and stress hypothesis in the context of the COVID-19 pandemic and the lockdown mitigation strategy. SocArXiv.

[4] Binder, C. (2020). Coronavirus fears and macroeconomic expectations. Review of Economics and Statistics, 102: 721-730.

[5] Andrews, K. R., \& David, D. K. (1987). The concept of corporate strategy. Homewood, IL: Irwin

[6] Wang, B., \& Gan, J. (1995). SWOT strategy analysis model. System Engineering Theory and Practice, $\quad(12), \quad 34 \quad-\quad 45$, doi:CNKI:SUN:XTLL.0.1995-12-006.

[7] Kurttila, M., Pesonen, M., Kangas, J., \& Kajanus, M. (2000). Utilizing the analytic hierarchy process (AHP) in SWOT analysis - a hybrid method and its application to a forest-certification case. Forest Policy and Economics, 1(1), 41-52. https://doi.org/10.1016/S1389-9341(99)00004-0

[8] Yang X. (2016). Application of a SWOT quantitative model in the strategic programming of theme park: a case of China dinosaur land in
Changzhou. International Business and Management, 11(2): 36-43

[9] Zeng, J. (2015). Research on the competitive strategy of real estate business based on improved SWOT (MA thesis, Chongqing Jiaotong University).

[10] Liu, R., Wang, Y., \& Qian, Z. (2019). Hybrid SWOT-AHP Analysis of Strategic Decisions of Coastal Tourism: A Case Study of Shandong Peninsula Blue Economic Zone. Journal of Coastal Research, 94(94), 671-676.

[11] Laroche, G., Domon, G., Gélinas, N., Doyon, M., \& Olivier, A. (2019). Integrating agroforestry intercropping systems in contrasted agricultural landscapes: a SWOT-AHP analysis of stakeholders' perceptions. Agroforestry Systems, 93(3), 947-959.

[12] SWOT. (2016). In A Dictionary of Business and Management (6th ed.). Oxford University Press.

[13] Saaty, T.L. (2005). Theory and Applications of the Analytic Network Process: Decision Making with Benefits, Opportunities, Costs, and Risks; RWS: Chalfont St Peter, UK.

[14] Saaty, T.L. (1988). What is the analytic hierarchy process? In Mathematical Models for Decision Supported. Springer: Berlin, Germany, pp. 109-121.

[15] Saaty, T.L. (2008). The analytic hierarchy and analytic network measurement processes: applications to decisions under risk. European journal of pure and applied mathematics, 1(1), 122196.

[16] 2021 Midyear Outlook for REITs and Commercial Real Estate: A Robust Recovery Ahead. Retrieved from: https://www.millionacres.com/research/reitstatistics/

[17]

Retrieved from https://www.crunchbase.com/organization/realphatech-corp/company_financials

[18] Retrieved from: https://www.conferenceboard.org/research/us-forecast

[19] Housing Market Update: 9\% Increase in Pending Home Sales is Slowest Growth Since June 2020. Retrieved from: https://www.redfin.com/news/housing-marketupdate-pending-sales-up-9pct/

[20] Key findings about U.S. immigrants. Retrieved from: https://www.pewresearch.org/facttank/2020/08/20/key-findings-about-u-simmigrants/

[21] US Apartment Market Evades Late Summer Slowdown As Rents Keep Rising. Retrieved from: 
https://www.costar.com/article/239921040/us-

apartment-market-evades-late-summer-slowdown-

as-rents-keep-rising

[22] Apartment List National Rent Report. Retrieved from:

https://www.apartmentlist.com/research/nationalrent-data

[23] Retrieved from: https://www.ustravel.org/research/travel-facts-andfigures 